\title{
Birthday, Culture, and Social Media
}

\author{
Marta Dąbrowska \\ Jagiellonian University of Cracow
}

\begin{abstract}
Life in the modern age is dominated by social media. What used to be very much a private affair, like birthdays, weddings, anniversaries, etc., is now celebrated in front of oftentimes the whole world, and not infrequently, through the medium of the language that is not our own.

The object of investigation in the present paper is the speech act of birthday wish sent to someone via Facebook. The analysis demonstrates that although the speech act has a universal aim - to show interest in another person and make them feel good, and although in many cases the language of conveying wishes, beside the native tongues, is the same, this notably being English, the lingua franca of contemporary world, the way the wish is expressed may differ markedly from culture to culture, thereby showing the underlying cultural values and norms of the users and of their native language use. The socio-pragmatic analysis presented here focuses on posts collected from personal profiles of British, Polish, Indian, and Armenian users, and investigates, among others, the choice of language, the formulaic vs. personalised character of the wish, and the character of strategies that make the wishes more personally oriented, with the aim to demonstrate visible differences across cultures regarding the way birthday wishes are phrased.
\end{abstract}

Key words: birthday wishes, speech acts, social media, culture, English as a world language.

\section{Introduction}

The turn of the $20^{\text {th }}$ and $21^{\text {st }} \mathrm{c}$. has introduced new ways of social coexistence and interaction among people as a result of the development of new 
technologies. What used to be approached, discussed, dealt with and celebrated within a small circle of family and friends has now become in many ways a public event. Social networking sites (SNSs), of which Facebook appears to be the prime example, have induced certain behaviours on the part of their users that, through common practice, have grown to be expected. One of them is to publicly share as well as acknowledge important developments in one's personal life. This has no doubt raised many questions on the part of the users as to how to express these meanings in order to meet, simultaneously, a number of goals to show interest in and support for one's SNSs friends by being at the same time personally oriented and intimate as well as genuine and publicly acceptable in one's actions by fulfilling certain expectations, and how to at the same time build one's self image that we, users, consciously or subconsciously wish to show to the world. One such situation that induces questions of this type is, no doubt, offering wishes to our friends on the occasion of their birthdays via SNSs.

The following discussion will focus on the analysis of birthday wishes excerpted from profiles of Facebook users in countries as different as the UK, India, Poland, and Armenia, but which may in many situations, though not always, share the use of English as a common language in the SNS communication. The seemingly simple and often conventionalised act of a wish, sometimes limited to barely a few words, and, as the preliminary analysis has demonstrated, frequently conveyed by means of English as the lingua franca of the contemporary world, when viewed both qualitatively and quantitatively shows that the common medium and the channel of communication do not always lead to a unified way of expression. The assumption to be demonstrated in the paper is that neither the common social situation (somebody's birthday), the shared discourse context (here that of Facebook), nor often the same language are able to fully hide cultural differences that lie behind the expression of the act of wish. The aim of the discussion is threefold - it is to demonstrate that: 
a) the universal concept of a birthday wish may vary both in its form and content from culture to culture, and reflect its main tenets, even when expressed by a common language,

b) in the era of superdiversity (cf. Blommaert 2018) SNSs users may and do use other languages than the native one in order to convey their meanings,

c) that English as a world language, when employed by non-native speakers, can be used on SNSs in diverse and creative ways.

\section{Superdiversity}

The modern world has been characterised by an increasing lack of geographical and normative boundaries that to some extent used to define people's lives up to the end of the 20th c. The sources of this can be found in the abolishment of strict political boundaries within larger areas like the European Union and growing migratory movements, which has in turn led to the formation of highly mixed international communities (cf. Vertovec 2006, Blommaert 2010), and most of all, the development of the social media. The latter are viewed as an important context in which to study developments of language and superdiversity. This concept was introduced by Vertovec (2006) who described it as the diversification of diversity in Western Europe, where the phenomenon was first observed and discussed as a potential source of trouble. With time, superdiversity has also been embraced as well as contested by sociolinguistics (cf. Varis 2016; Goebel 2017; Stæhr 2017). As has been concluded, it is social media that are particularly interesting in the study of superdiversity as sites which "offer endless possibilities for communication and self-expression across national and cultural boundaries" (Stæhr 2017:171; based on Varis and Vang 2016). They are characterised by "plurality, heterogeneity and polycentricity of semiotic and linguistic resources and normativities" (Leppänen and Elo 2016:112). As Varis and Wang (2016) also claim, the Internet is as a social space which is "saturated with opportunities and aspirations where one is able to indulge in infinite creativity in imagining and constructing both self and other." 
One needs to remember that the virtual world, notably that of social media, is a space where not only the traditional norms of interaction and linguistic expression have been suspended (cf. Danesi 2016), but also that notions known from offline world may take on a different meaning online, even though we "talk about (...) new modes of internet communication very much in ways reflecting a pre-internet complex of social relationships" (Blommaert 2018: 86). Blommaert (ibid.) gives examples of concepts like 'friend' and 'like', which in the SNSs environment take on a very different meaning from the one used in the real world, and as he claims, for instance, "[n]o one needs to actually like an update in order to 'like' it" (ibid. 86-87). Therefore also the observations made in this paper regarding the cultural background of the wishes analysed here must be considered as those reflecting online norms and tendencies followed by the respective users in given countries, not necessarily their offline standards.

\section{Facebook and Birthday Wishes}

One of such distinctive aspects of the online interaction in reference to offering birthday wishes is the fact that, as regards social media, and especially Facebook, the context of hereby analysis, it in many ways induces the wishes by sending its users Facebook and email reminders. For this reason the value of such wishes may be seen as diminished, compared to face-to-face, phone-call or email wishes. As West and Trester (2013:148) suggest, "[t]he act of remembering is an act of friendship because it is an opportunity to anoint positive face, but also because it requires an effort on a friend's part." This suggests, similarly as the comments above concerning the concept of friend in the offline and online worlds, that birthday wishes posted on someone's Facebook profile may be viewed as less valuable and honest. As Viswanath et al. (2009: 1) claim "over $54 \%$ of the interactions between the infrequently interacting user pairs [...] can be directly attributed to Facebook's birthday reminder feature," which arouses doubts on the part of some scholars that the wishes may indeed constitute true manifestations of facework and politeness (cf. West and Trester 2013). 
Interestingly, wish, and specifically a birthday wish as a speech act does not often feature as a subject of analysis. According to the speech act theory, wish would be classified as an expressive act, together with e.g. thanking, apologising, greeting, etc., i.e. one by means of which the speaker expresses a psychological state towards the hearer (cf. Searle 1976, Archer et al. 2012). It can no doubt be also viewed as an act that conveys politeness, and according to Brown and Levinson's classical theory (1978/1987) as a marker of positive politeness. Although the two scholars do not refer to the wish directly, one of the strategies discussed by them that appears to be fitting here is that of giving gifts, by which they understand goods, sympathy, understanding or cooperation (ibid.: 129). Positive politeness aims to satisfy the hearer's wants which in this case need to be understood as wants to be "liked, admired, cared about, understood, listened to and so on" (ibid.). A birthday wish appears to fulfil these criteria particularly closely, for everyone, as it might seem, likes to be remembered about and be the addressee of wishes on one's day of birth, which is celebrated in a grand way in many cultures. It is important to remember, however, that while in the western cultures, e.g. the Anglo-Saxon ones, birthday is an important aspect of one's life, even for children, in others, for instance Chinese, birthday is not thought of as an important occasion or information to be shared with others (cf. Liao 2000), which makes any observations made here very much culture-related.

Wishes are sometimes analysed jointly with another expressive, the speech act of congratulations (cf. Nurgalieva and Saidasheva 2017), and wishes with the sense of "I congratulate you on your birthday" can also be found in the corpus that has been collected for the analysis here. Yet, according to Can (2011), who quotes some respondents in her MA thesis, people do not often think that birthday "rises to the level of deserving congratulations" (Can 2011:26), unless someone has reached an advanced age of 80 or 90 or more.

The concept of a wish may naturally be ambiguous. It may, for instance, mean a desire for something that is not easily attainable, something that is unlikely to happen, whereby its reading gains negative connotations, certainly not fitting the occasion of one's friend's birthday. In the sense discussed here 
wish can rather be defined, following Merriam-Webster Dictionary online, as "an invocation of good or evil fortune on someone." This, however, can be expressed in various ways.

According to Mekeko (2001, after Nurgalieva and Saidcheva 2017:1293), wishes can be subdivided into standard and individualised ones. The reasons for the use of the conventionalized forms may be, as Mekeko (ibid.) claims, e.g., an insufficient familiarity between the interlocutors; lack of time to come up with more unconventional form of wishes; lack of need to express a more personal attitude towards the addressee on the part of the speakers, or else, when the context of communication is very formal. The more individualised form of wishes is used, on the other hand, when the sender wants to communicate a more personal attitude towards the addressee or when s/he wishes to strengthen the bond between him-/herself and the addressee ${ }^{1}$.

The above observations lead to a conclusion that many polite speech acts have a formulaic character, they are so-called conversational routines or interactional rituals (Coulmas 1981a: 3), so their content tends to matter less than their function. However, as Lubecka (2000:61) argues, "even reduced to language clichés, these speech acts are indispensable for interactional success as they reflect shared societal knowledge about politeness." In other words, whether formulaic or not, their use is important for the smooth coexistence between friends and acquaintances. When analysing wishes as representatives of speech acts, it needs to be remembered, though, that a number of languages may share the same speech act, conceptually, but the standard form typically used by their speakers may vary and be subject to different conventions of use (cf. Searle 1975, Blum-Kulka 1983). In other words, they follow different sociocultural scripts (cf. Lubecka 2000:61). And thus, in English the standard form of a birthday wish is Happy birthday, and in Hindi जन्मदिन मुबारक (Janamdin Mubarak), i.e. both form stress the celebration of the special day, while in Polish one of the most traditional forms of wish is Sto lat, i.e. lit. '(may you live) a hundred years', and thus it is more oriented towards the future. In Armenian, on the other hand, the typical form seems to be 2 anphullnp (Shnorhavor), 
which does mean 'congratulations', and in the form O\&nz\&nn 2 \&nphulyn (Tsnundd shnorhavor) it means 'congratulations on your birth'. One aspect of the following analysis will therefore be to discuss the use of the standard/formal vs. individualised form of the collected wishes, both quantitatively and qualitatively, in order to see which forms dominate in the respective languages online, and also to establish whether the standard and personalised forms find their literal reflection also in the wishes offered in other languages than the native one, or whether the foreign language wishes rely on the standard form typical of that language and culture.

\section{Cultural Dimensions}

Analysing and discussing the same speech act across different languages, and, additionally, in a language that is not one's own is a complex issue. As Kotorova (2014:187) argues, one has to take into consideration a number of factors, viz.

1) many sociopragmatic factors (for example, the degree of influence of the age factor or the social status factor on speech behavior can substantially vary in eastern and western countries), 2) general cultural norms (the rules of speech etiquette and ideas of politeness are not the same in different communication societies), and 3) situational norms (predominance of communication belonging to vertical or horizontal type, observance of the distance between interlocutors). Influence of the linguistic factors is connected to the peculiarities of the language code used by interlocutors.

It would be impossible to take all of these factors into consideration in the limited space of this paper. The framework of the following analysis will, therefore, be the gender as well as age of the users viewed broadly from the point of view of the cultural characteristics assigned to a given culture and country, with, as mentioned above, the aim of investigating whether the norms show themselves in the form and meaning of the analysed wishes (and thus, where the cultures may differ in respect of offering birthday wishes, especially online), and particularly so, if they still manifest themselves when the authors decide to phrase them in a foreign language. 
As Pauwels (2012) claims, investigating cultural aspects falls broadly into studies initiated by Hall $(1966,1976)$, which focus on the distinction between high and low context cultures and those which have stemmed from Hofstede's research (1980, 2001) concerning business and management-oriented studies, with most contemporary studies following in the footsteps of the latter and filling in the gaps concerning various countries (cf. Kirkman et al. 2006). It has to be said that Hofstede's dimensions and results concerning respective countries have aroused serious controversies on the grounds that the findings are based on corporate culture, not on general everyday relations; analyses conducted by other scholars have also produced different quantitative results (cf. Trompenaars 1997). It is an undeniable fact, however, that findings concerning Hofstede's dimensions, viz. High/Low Power Distance, Individualism/Collectivism, Masculinity/Femininity, High/Low Uncertainty Avoidance, Long/Short-Term Orientation, are most complete as regards different cultures and account for many countries. The website Hofstede Insights offers calculated values and descriptions concerning three of the four countries discussed here, i.e. the UK, India, and Poland. Armenia, however, is still missing in the analysis. Yet, the values for Armenia have been calculated based on this model by other scholars, viz. Khzrtian and Samuelian (2012), Khachatryan et al. (2014); similar findings can also be revealed $\mathrm{n}$ the discussion on the website devoted to Business Management in Armenia (2010) at http://www.freeonlineresearchpapers.com/business-management-armenia.

Therefore, despite the obvious weakness in the applicability of the model to the non-business world, due to the completeness of data for comparison, the five dimensions may be a point of reference for our further discussion.

It will therefore be of help to list the heretofore findings concerning the four countries side by side with the values and/or description of the state of each culture in relation to the five dimensions (with descriptive values for Armenia, as the numerical ones have not been calculated in the sources cited here): 


\begin{tabular}{|c|c|c|c|c|}
\hline & UK & India & Poland & Armenia \\
\hline Power distance & $\begin{array}{l}35 \text { (inequalities } \\
\text { should be } \\
\text { minimized, fair } \\
\text { play) }\end{array}$ & $\begin{array}{l}77 \text { (appreciation } \\
\text { of hierarchy and } \\
\text { top-down } \\
\text { structure) }\end{array}$ & $\begin{array}{l}68 \text { (hierarchical } \\
\text { society) }\end{array}$ & $\begin{array}{l}\text { High power } \\
\text { distance, } \\
\text { typical of } \\
\text { hierarchical } \\
\text { cultures, } \\
\text { periods of } \\
\text { foreign rule }\end{array}$ \\
\hline $\begin{array}{l}\text { Individualism } \\
\text { vs. collectivism }\end{array}$ & $\begin{array}{l}89 \text { (highly } \\
\text { individualistic } \\
\text { and private) }\end{array}$ & $\begin{array}{l}48 \text { (both } \\
\text { collectivistic } \\
\text { (need to belong } \\
\text { to larger social } \\
\text { framework) and } \\
\text { individualistic) }\end{array}$ & $\begin{array}{l}60 \\
\text { (individualistic } \\
\text { society, loosely } \\
\text { knit social } \\
\text { structure) }\end{array}$ & $\begin{array}{l}\text { Has shifted } \\
\text { from } \\
\text { collectivist } \\
\text { Soviet society } \\
\text { to an } \\
\text { individualistic } \\
\text { one }\end{array}$ \\
\hline $\begin{array}{l}\text { Uncertainty } \\
\text { avoidance }\end{array}$ & $\begin{array}{l}35 \text { (happy with } \\
\text { the unknown) }\end{array}$ & $\begin{array}{l}40 \text { (acceptance } \\
\text { of imperfection) }\end{array}$ & $\begin{array}{l}93 \text { (very high } \\
\text { preference for } \\
\text { avoiding } \\
\text { uncertainty, } \\
\text { need for rules) }\end{array}$ & $\begin{array}{l}\text { Open to } \\
\text { uncertainty, } \\
\text { importance of } \\
\text { trust } \\
\text { (preliminary } \\
\text { finding) } \\
\end{array}$ \\
\hline $\begin{array}{l}\text { Masculinity vs. } \\
\text { femininity }\end{array}$ & $\begin{array}{l}66 \\
\text { (competition, } \\
\text { achievement, } \\
\text { success) }\end{array}$ & $\begin{array}{l}56 \text { (masculine in } \\
\text { visual display } \\
\text { of success and } \\
\text { power) }\end{array}$ & $\begin{array}{l}64 \text { (masculine } \\
\text { society, equity, } \\
\text { competition and } \\
\text { performance) }\end{array}$ & $\begin{array}{l}\text { The culture is } \\
\text { masculine, } \\
\text { typical of } \\
\text { "honor } \\
\text { societies," } \\
\text { saving face, } \\
\text { history of } \\
\text { foreign } \\
\text { oppression }\end{array}$ \\
\hline $\begin{array}{l}\text { Short vs. long } \\
\text { term } \\
\text { orientation }\end{array}$ & $\begin{array}{l}51 \text { (middle- } \\
\text { range value, } \\
\text { preference hard } \\
\text { to determine) }\end{array}$ & $\begin{array}{l}51 \text { (no dominant } \\
\text { preference, time } \\
\text { is not linear) }\end{array}$ & $\begin{array}{l}38 \text { (more } \\
\text { normative than } \\
\text { pragmatic) }\end{array}$ & $\begin{array}{l}\text { Long-term } \\
\text { orientation } \\
\text { (preliminary } \\
\text { finding) }\end{array}$ \\
\hline
\end{tabular}

The reference to the cultural dimensions need to be treated as only tentative, however. In view of the aforementioned criticism it is unclear whether and how the above values will manifest themselves in the birthday 
messages offered by representatives of the four cultures. One might assume, for instance, that high individualism may lead to a very individualized form of the wishes, yet at the same time it may mean that individualistically oriented users may not care in any special way about the positive face of others but more about themselves. High power distance may lead to elaborate wishes addressed to friends who are senior to the senders either in social rank or age, etc., but the same result might be an outcome of higher collectivist attitude, i.e. in order to attend to their friends' face well-wishers may want to sound particularly caring and attentive. The following analysis will therefore proceed from the examples and subsequently the differences detected in the material will be discussed with the aim to find a possible interpretation for them, also as regards the dimensions provided, in order to see if any of them can account for the tendency found in the form of the wishes analysed here.

\section{Analysis of Data}

Type of wishes

As indicated above, the most general subdivision of wishes that we can start our analysis with is that into formulaic/conventionalised wishes vs. individualised/personalized wishes. Investigating the material in this respect will allow us to conclude

a) what the typical form of wishes used online in the four respective cultures was as regards the native tongue,

b) what Anglicised or other language forms users of those tongues as a second or foreign language chose.

The subject of analysis were 800 wishes collected from personal profiles of British, Indian, Polish, and Armenian users, divided into four respective subcategories, i.e. 200 wishes from each of the cultures. They were collected from the profiles of addressees in a continuous way as they appeared on the wall of respective persons, and thus the number of women and men senders is not equal, yet efforts were made to assure as balanced representation of the four possible dyads (woman-woman, man-man, woman-man, man-woman) as possible. Also, the addressees were chosen in such a way that there were, 
respectively, senior recipients of both genders, middle aged recipients of both genders and younger recipients of both genders, so as a result each of them was an addressee of wishes ca. 33-34 times.

Before the results of the qualitative and quantitative analyses are presented, it needs to be stated that the choice of languages found in the four cultural groups varied considerably. The overview of the linguistics choices presented the following distribution:

English - in $64.3 \%$ of the total

Polish - in $21.9 \%$ of the total (82\% of the Polish posts)

Armenian - in $7.2 \%$ of the total (14\% of the Armenian posts)

Russian - in $1.75 \%$ of the total (7\% of the Armenian posts)

Hindi - in $1.25 \%$ of the total ( $5 \%$ of the Indian posts)

It may thus be observed that all the groups, besides the British, chose to use English as a language of the wishes (addressed to persons of the same nationality as the senders themselves), yet to a varying degree, beginning with almost completely English wishes sent by Indian users, through a large share of English-language wishes, but also Russian (next to Armenian) found with the Armenian users, and ending with visibly Polish-dominated wishes sent by the Poles. The above distribution is also a valuable source of information about the status of English in the analysed cultural groups as well as the visibility of the respective languages in the social media.

The question of the use of conventionalized vs. personalized wishes has demonstrated that there are visible differences in the ratio of the type of wishes observed in each culture. A very interesting subdivision can be found in two groups, i.e. Brits and Poles sharing similar values on the one hand, and Armenians and Indians forming another subcategory. We shall take the British group as primary due to the fact that English, which is used by other groups too to a varying extent, is their native tongue and in this sense the British users' linguistic choices constitute the prototype of the most natural spontaneous behavior in the context discussed. Thus, the Brits chose the conventionalized form of wishes in $66 \%$ of the cases (the strictly formulaic form in $40 \%$ and somewhat relaxed, yet still conventional in $26 \%$ of posts), while $33 \%$ of the 
wishes had a more personalized character. This, then, sets a certain standard for the other three groups to compare to. Of those, the closest in behavior were the Poles. They chose the conventional form in $65 \%$ of the posts (strictly conventional in $42 \%$ and somewhat relaxed in $23 \%$ of the posts), and the personalized form was found in $34 \%$ of cases. This mirrors the British group almost exactly, however, it needs to be stated that the majority of the wishes found in this group were formulated in Polish - only 42 i.e. $17 \%$ of the wishes were offered in English. This shows a very natural, spontaneous (considering the CMC character of the medium) behavior of the wishers and therefore it may be concluded that when using their first language about one third of British and Polish users, respectively, choose to behave more unconventionally, thereby marking their more individualistic character in this speech act, and also possibly confirming to an extent the higher degree of individualism claimed for the two countries by Hofstede.

On the other hand, Indian users, for whom English tends to be their second rather than foreign language, and thus a more natural choice, behave in more restrictive ways. In their case, $78 \%$ of the wishes had a more conventionalized form (55\% strictly formulaic and $23 \%$ more relaxed), while the personalized way of wishing others happy birthday was recorded in $22 \%$ of the posts (and thus only one fifth of the posts). Indian users also at times chose their native tongue (Hindi in the posts chosen for analysis), but this was found in only 10 items (i.e. 5\% of the examples), the vast majority having chosen English. Similarly, Armenians, for whom English is certainly a foreign rather than the second language (and who chose to express wishes also in Armenian in $14 \%$ of cases and in Russian in $7 \%$ ), showed very similar preferences irrespective of the tongue when compared to those of Indians. Thus, they went for conventionalised forms in $77 \%$ of cases $(56 \%$ with strictly formulaic forms and $21 \%$ in a more relaxed manner) and only $22 \%$ of the wishes had a personal character. Taking into consideration that this was true of both Indians, who chose English as their medium of expression by far the most, and of Armenians, who expressed their wishes in three languages, mostly, however, in English, this distribution shows a lower degree of individualism, which confirms the 
findings of Hofstede and of Business Management in Armenia (still seeing Armenia as a collectivist country) rather than Khztrian and Samuelian (2012), who claim Armenia has become more individualistic now.

Some examples to illustrate the more individualized character of the wishes to be found in the four groups are as follows: Happy birthday, X! Let me know when you're down south $x$; Cousin, let's go bowling! Happy birthday; Happy Birthday to the best cuddle ever hope you have a fantastic day. BIG HUGS $\mathrm{XXXX}$, Dear $X$, a joyful day with love and nice surprises and only the best things in life we wish you xоoxoxoox; Wszystkiego najlepszego! (od rana myślałam nad treścią życzeń ) ['All the best (I have been thinking about the content of the wishes since the morning)']. On the other hand, in respect of the most typical conventionalized form of wishes for the groups under investigation, the overview of the data has demonstrated that the most popular form of the English wishes, both in the native and non-native group was simply the expression Happy Birthday (found in 165 cases in the British posts, 13 of Polish posts, 126 of Indian posts and 92 of Armenian posts). Also very popular among most of the groups was the form Many happy returns of the day and their variations, found, respectively, in 4 wishes used by the Brits, 23 by Indians, 6 by Armenians and 1 by Poles. Other forms featured more infrequently.

Other than English, the most frequent form found in the data was Shnorhavor, recorded 47 times in the Armenian samples, which was followed by Shnorhavorum em 'congratulations' (27 times), Tsnundd shnorhavor 'happy birthday' (6 times). Armenian users also frequently chose to express their wishes by means of the Russian $S$ dnem rojdenia 'on the day of birth' (37 times), and Pozdravlyayu I congratulate' (recorded 17 times). The most frequent form used by Poles was Wszystkiego najlepszego 'all the best' ( 81 instances) followed by Sto lat 'a hundred years' ( 55 times). Barely visible, due to the preference of English, were Hindi forms, and these were Janamdin Mubarak happy birthday' (2 times), janamdin shubhkamnae ki hardik 'heartfelt birthday wishes' (2 times). The overview of these forms allows us to observe some cultural trends already adduced above. While most of the cultures here focus on the actual day of birth as the reason for congratulations and celebrations, i.e. the present-day 
orientation, the Polish form Sto lat in particular, and to some extent Many happy returns of the day shift the perspective into the future, attempting to invoke the assurance of a long life on the addressee of the wishes. Whether this particular feature might be a reflection of uncertainty avoidance marking the Polish character particularly strongly is hard to prove, yet this form of wish might reflect some sort of anxiety caused by the unknown indeed.

\section{Personalisation of wishes}

Having discussed the most typical form of the recorded wishes, notably those phrased in English, we will now examine items recorded in the posts that make the wishes more personalized (though they could naturally be found in the more relaxed conventional options too). The items analysed below will examine such elements as terms of address, emotionality markers, additional items added to the conventional forms, affective forms, the use of humour and informality, references to other issues unrelated to birthday directly, and multimodal aspects of the wishes reflected in cards, photos, films, and the use of coloured formats.

\section{Forms of address}

By far the most frequent as well as most personally oriented elements of the wishes that make the reading much more intimate and highly personalized are forms of address. As such they single out the person by naming him/her and making them understand that the wishes are only for them and none other. In such cases even the most conventionalized forms become more personally marked. It needs to be stated right away, though, that the terms of address found in the samples are of a very diverse type. While some forms indicate great informality and diminish the distance between the sender and the receiver, others mark a greater distance between the interlocutors; while the former are markers of solidarity, the latter carry more conventional politeness. To be sure, while the native English senders never used forms with honorifics and official titles like $M r$ or $M r s$, etc., using the first name or a nickname also when writing to a very senior person, the formal options could be found in the 
posts collected from Armenian and Indian profiles; Polish wishes, however, did not possess them, either. Altogether, the distribution of the forms of address across the four groups presented itself as follows: British 134 (addressing women 66, men 68), Armenian 126 (addressing women 97, men 29), Indian 110 (addressing women 44, men 65) and Polish only 85 (addressing women 51, men 34). It thus shows another very interesting difference, this time juxtaposing primarily Brits, with $134 / 200$ posts and Poles with $85 / 245$ posts. In this case a conclusion may be attempted that, firstly, when interacting with another person, also online, in the British culture it is pragmatically typical and expected to address them by their first name, while in Polish it is optional. Secondly, it might be deduced that by choosing not to use forms of address so often when posting wishes Poles possibly do not like to raw the other person's attention by means of calling their name, and prefer to make their posts personalized in different ways, which may again point to a higher level of uncertainty avoidance in the Polish culture. On the other hand, the fact that Armenian and Indian senders used forms of address often, including titles and honorific may be an indication of high power difference still to be found in the society and the need to show respect to those who are senior both in terms of age and/or position.

What also needs to be commented on is the use of terms of address of various kinds in respect of the gender and age of the addressee, for the numerical values are not always balanced here. The most evenly spread numbers are to be found in the posts of the British, where the first name is used to both young and old, men and women alike, though possibly with a slight preference for the latter. And thus women addressed young women 21 times and older women 18 times. Men addressed young women 19 times and older 17 times. Women addressed young men 11 times and older ones 15 times, and finally men addressed young men 11 times and older men 21 times. It seems then that it is young men that are addressed directly least often, and young women most often, yet the difference is slight in terms of quantity. This is where possibly the need for equality mentioned by Hofstede becomes visible most. Qualitatively, however, one needs to stress that it is mainly young women 
that evoked the use of shortened forms of names or terms of endearment, e.g. Nico, Nic, m'dear, love, gorgeous, loveliness, lovely lady, beautiful one, etc., used by both men and other women, the latter marking their solidarity this way.

A different way of using names is to be found in the other three cultures, in which the distribution is not equal. It is most common for Polish women to address other women, and for men to address other men. When it comes to addressing persons of the opposite sex, the frequency visibly dwindles, which can be seen in the following distribution: women to young women 18 times and older - 19 times, men to young men 10 times and older - 18 times, women to young men 3 times and older 13 times, and finally men to young women 4 times and older -2 times. A possible interpretation is that of solidarity between persons of the same sex, and possibly of certain cultural restrictions and fear of one's intentions being misunderstood in the mixed-sex contexts.

A similar situation can be seen in the Indian samples, with possibly one interesting alteration. It seems that men are most willing to address other men, which happened 20 times to young men and 22 to older ones. A similar, but less frequent choice of terms of address was recorded with women - 15 times to younger women and 16 to older. When men chose to address women, however, they did it much less frequently when sending wishes to young ones -9 times, but to older 14 times. Finally, the greatest possible cultural restrictions are to be seen when women address men - the young ones are addressed 6 times and older - only 2 times. The sample is too small to draw reliable conclusions, yet it might be assumed that in the Indian culture, which is highly masculine and patriarchal, addressing senior men by younger females in the (semi-)public online context is a considerable face threatening act, hence the limitation is possibly here.

Finally, the Armenian sample shows yet a different pattern. What strikes the observer is a very high number of names found in female-female wishes, both to young women -33 and older ones -36 . This is certainly not matched by the male-male wishes, where young men are addressed 6 times and older 16. The mixed-sex wishes create yet another pattern. To have men address 
women of either age on Facebook is a very rare situation, with the younger ones addressed 3 times and older -4 times. Finally, when women address men, there is a visible discrepancy here, as young men are addressed only 7 times, and older as many as 23 , which appears to be in opposition to the Indians. There seems to be a certain cultural ban on directly addressing persons of the opposite sex while sending wishes on Facebook (and thus adhering more to conventions), with the exception of older men, who appear to deserve to be acknowledged with respect in public.

What needs to be examined in addition to the above comments are the actual forms, as already indicated above, for they are not of equal value, either. While, as already indicated, the British used the first name indiscriminately, e.g. Mike, Sheila, Barbara, Andrew, etc., Poles introduced the variation in the formality of the forms, the former being indicated by the vocative form, the latter by nominative and also, additionally, the use of the diminutives, e.g. Wojtku (Voc.) vs. Wojtek (Nom.) vs. Wojtuś (Nom., Dim.), Piotrze (Voc.) vs. Piotr (Nom.) vs. Piotruś (Nom., Dim.), Maćku (Voc.) vs. Maciek (Nom., Dim.) vs. Panie Macieju (Title + Form.), Renato (Voc.) vs. Renata (Nom.), koleżanko ('friend', Form., Voc.) vs. kochana ('dear, love', Nom., Endearment). Both Indians and Armenians chose to mark formality by means of honorifics, i.e. the Indian honorific ji (6 times), next to or in the place of the English equivalent Sir (5 times) or Ma'am (5 times), or else terms of address used to more senior or unknown people as Mama, Didi, Aunty, Akka, etc., and the Armenians went for the English form Mrs ..., Mr ... or Professor..., Doctor.... . By far the most frequent (found in as many as 90 cases), however, was the use of the term of endearment jan attached to both first names and surnames, which stressed the strong feeling of solidarity and camaraderie most of all in this culture. At the same time especially the Armenian wishes in English contain numerous cases of the word dear preceding either first names or the formal titles like Mrs or Professor, which makes the wishes found in this culture distinctive - 32 cases of the word and 5 in the superlative form dearest have been identified in the material (by comparison, only 4 instances were recorded in the posts of the Brits), and their presence is no doubt motivated by the typical Armenian term 
of endearment jan found in Armenian as well as English and Russian language posts.

Another form of personalization appears to be a more effective manner of conveying wishes. This, as the scrutiny of the material has demonstrated, was achieved by means of a number of strategies. They can be divided into the following categories: a more elaborate form and content of the post, stronger forms of affective words, humour and/or informal language, and reference to other issues beside birthday. The list needs to be enriched with non-linguistic aspects too, i.e. the use of emoticons and punctuation and other multimodal aspects, namely the use of colour backgrounds, uploading birthday cards, photos and Facebook films. As can be seen, the choice of options is rather rich.

\section{Elaboration of form and content}

This strategy can be illustrated by such examples as e.g. Happy, happy birthday! Wishing you lots of joy, peace and success, always. May this year be one of great, happy memories, and bring to you all the happiness and luck! Stay blessed...; Happy birthday $X$, have a wonderful day. Lovely to see you yesterday. Lots of love $x ; X$ jan, happy birthday!! Wish you endless love and happiness!!!; $X$ jan!!! I wish you all the best!!! Be very happy, healthy and wealthy!; Many Many Happy returns of the day to the most loving and elegant person. May god bless you all smiles and happiness forever. Such forms can be found in all the four analysed cultures and also in forms addressed to women and men, young and old, but as can be expected, the frequencies and patterns of use will vary. Interestingly, it is again that the distribution shows similarities as regards wishes offered by the British and the Polish users, especially when we consider the fact that Poles chose to write in Polish far more often than in English. What could be observed were 80 instances of such elaboration for the Brits (53 times used by women and 27 by men), while Poles opted for it 79 times, 52 times in posts generated by females and 27 times by males. While it was again women that chose this strategy more, it could be seen that British women did it both with other women and with men $(16+15,12+10)$, while in the Polish group the strategy in the posts to young men was severely limited, 
while female-female posts abounded in it $(15+21,2+14)$. Posts sent by men contained fewer instances of the kind in both cultures, with only older Polish men attracting more such elements, other than that the distribution being as follows: men-men $4+14$, men-women $5+4$ in the Polish group and men-men $4+8$ and men-women $8+7$ in the British group. The difference between the frequency of use in posts sent by women and men does not surprise in view of the typically greater affectiveness and rapport orientation of females rather than males towards their interlocutors (cf. Tannen 1990; Holmes 1995; Dąbrowska 2007ab; 2019).

As regards the two other groups, their choices were different. While Armenians used this strategy altogether 62 times, when broken into gender groups, the distribution showed that it was primarily women who opted for this personalization tool, 56 of them, though they never used it when sending wishes to younger men (women-women 19+22, women-men 0-15), while men chose this strategy only in a few cases, i.e. 6 times (men-men $1+2$, men-women $0+3$ ). This points to a very marked rift in the typical female and male behavior of Armenians online, with men restricting displays of affectiveness very markedly and women doing just the opposite, also in English.

Yet another possibility could be detected among Indians. Their use of elaboration of form and content was lowest of all the four groups, with 45 items in all. The figures in the particular gender and age slots were altogether limited, but lowest of all in female-male combinations (much like in the Armenian group, yet in a reversed order), where the number was $4+0$. The female-female communication did not show a massive use of the form, viz. 10+12, while the choice of the strategy by men was evenly spread, i.e. men-men $4+3$, and menwomen $4+8$. One may then wonder whether it is that Armenian women do not show high affectivity to young men for fear of being described as promiscuous, while Indian women fear showing high emotionality to older men not to be viewed as childish or lacking respect towards their interlocutors.

A substrategy next to the above-mentioned one is the use of more affective forms of certain vocabulary items, like adjectives or adverbs, attained through the use of superlatives, reduplication or by means of capitalization, e.g., 
Happiest birthday darling X; Happy, happy birthday!!!; I wish you endless happiness and joy!; My dearest lecturer happy B-day!; Wish you a very Happy Birthday \& many many more to come; Happy birthday...X....GOD BLESS YOU $A L W A Y S \ldots$. These are described as a separate strategy because they may appear in otherwise short and simple conventional forms of wishes, typically as a single item. The use of such forms stresses the positive politeness and warm feelings the sender has for the addressees, which makes the reading more personalized than only a conventional wish.

The examination of the choices made by the four groups demonstrated a certain difference in numbers between the British, who used it 25 times $(15+10)$, which is itself not a highly popular strategy, and the other four groups, where the numbers were even lower. This time it was the Indian group that manifested it in a fairly visible way, by choosing it 15 times, with women opting for it 11 times and men only 4 . The Polish group followed, with 12 items in all (women 8, men 4), and, surprisingly, the Armenians, with the figure of only 10, women 9 times, and men only 1 . Thus, it appears that displays of strong affectionate feelings via the choice of vocabulary is not what users of the four cultures typically employ in relation to their friends in front of the public. Yet, as can be immediately seen, it is always women in all the four groups, with similar proportions that choose this aspect of conveying birthday wishes more, which thereby confirms earlier findings concerning a higher rate of affective displays on the part of women once again (cf. Holmes 1995; Dąbrowska 2007ab; 2019).

\section{Humour and informality}

A strategy that numerically follows the above is that of humorous and/or informal comments or elements of the wishes. This may at first appear to be an unusual strategy found in wishes, and one that should make them more personalized. However, Brown and Levinson (1978/1987) do specifically list the strategy of joking under positive politeness (cf. p.124). There are also a few other strategies in their theory that could account for the use of joking and informality as markers of positive politeness, viz. using in-group language, using 
jargon or slang and conveying that $\mathrm{S}$ and $\mathrm{H}$ are cooperators by showing optimism, which humour and informality certainly are markers of.

The examples of this strategy found in this category can be illustrated by the following: Happy B'thd, Barbara! Love to you both; Happy birthday for yesterday cuz hope u had a great day xx; Many Merry Returns, Mary!; Awrrabest $X$ hope you had a fabulous day!! X; Herdfy Bijjyy; Wish you a v $v$ happy birthday and stay blessed; Happy Birthday!! Have a super celebration!! Cheers!!; Happy bday sweety; Happy birthday ron cha cha!; Happy Birthd; Happy b'day:-); Zdrówka i żeby żadne stwory nie chciały kłaść łapy na Twoim złocie (Good health-DIM, and hopefully no monsters will want to put a paw on your gold); Wszystkiego najlepszego młodzieńcze! ('All the best young man'); Wszystkiego najlepszego! (od rana myślałam nad treścią życzeń) ('All the best! (I have been thinking about the content of the wishes since the morning)'); Happy Bday to you; happy bday dear $(-)$, congrats our dearest miss $X$, rather than humour (e.g. happy-mappy). The scrutiny of the samples has demonstrated that three cultures: Indian, British, and Polish employ humor and informality in birthday wishes to a considerable degree, while Armenian users rely on it to a very limited extent. The culture that makes use of this strategy most are, surprisingly, Indians. The Indian culture representatives made use of this strategy 54 times, with, however, a certain preference for it among men, who used it 29 times, while women only 25. The distribution of this strategy was fairly even as regards gender (women-women $10+6$, women-men $5+4$ vs. men-men $9+8$, men-women $4+8$ ). When it comes to the difference between the use of humour and informality, however, there is a considerable discrepancy between the two, for humour was in fact found in 5 instances while informality in as many as 49 . This points to the clear preference of Indians for using informal, and, as the scrutiny demonstrated, abbreviated language, which goes hand in hand with the great tendency to use abbreviated English found in other studies too (cf. Dąbrowska 2013, 2018).

The British users, who tend to be perceived as a nation which likes dry humour considerably, used this device 50 times in total. This number, however, breaks into 13 items of humour and 37 of informality, which points to a 
dominance of informality, but also a higher share of humour when compared to the Indian group. In the British group it was actually women who made use of the strategy more often, i.e. 32 times, compared to men - 18 times, and the distribution across the pairs was fairly even: women-women $15+6$, women-men $6+5$, men-men $3+3$, men-women $9+3$. This result shows, though only tentatively, that, although the tendency to be informal in the British culture is generally observed, there might be a higher frequency of it among and towards the younger generation.

This ratio of humour vs. informality is reversed when the Polish examples are concerned. According to the data, although third highest as regards the total number of items here, viz. 41 , it is Poles who made use of the strategy of humour most, for humorous items were recorded 27 times, while informality only 14. This distribution shows that Poles (notably men) do not feel at ease offering serious, bombastic wishes to others in public, for, interestingly, this time women made use of it 16 times, and men 25, but women never seemed to resort to it when addressing young men (women-women $3+6$, women-men $0+7$ ) and men were reluctant to use it with older women (men-men $6+11$, menwomen $7+1$ ), which shows interesting rules possibly underlying interaction in the Polish culture.

The Armenian users, on the other hand, made use of the strategy in a very restrictive way. Out of the 15 instances in all it was women who used it, as there were 13 examples noted (women-women 9+2, women-men $0+2$ ), while there were only 2 instances found in men-men (with young addressees) wishes. Also, it is worth noting that most of the cases found here were typically examples of informalities, like Happy Bday to you; happy bday dear (-) wish u a very positive $(-)$, congrats our dearest miss $X$, rather than humour (e.g. happymappy), and these were more imitations of the British acronyms, so this allows us to draw a conclusion that offering wishes, especially in a semi-public SNSs context is a serious issue in Armenia, one that should not joke about, which in turn may stem from the tradition of making toasts on festive occasions that is still very strong in this culture. 


\section{Other topics}

An aspect which definitely makes the wishes more personalized than not are references made by the wishers to other issues beside birthday itself and wishes connected with it. Examples found in the sample included, e.g., recollections of a meeting, memories from studies, questions concerning children, praises concerning achievements, etc., as in the following examples:

Happy birthday X! I think I walked by you on GWR yesterday but didn't realise until too late to say hi. Hope you're good and that the recording is going well. I don't suppose the blacksmith is in the mix ha ha; Happy Birthday, X! Eva and I wish you Health and Happiness Always! Have a wonderful time. Go to Mainland China or some other restaurant that may have opened recently. Will look forward to seeing the pictures; Wszystkiego co najlepsze! Dzięki za bycie inspiracją, $W$ zmienianiu rzeczywistości dookoła na lepszą. ('All what is best. Thanks for being an inspiration in the changing of the reality around for a better one'); Happy Birthday $X$ and thank you for lunch today! Enjoyed it so much!; Very Happy Birthday, $X$, from Jan and me! Hope you and $Y$ can visit us in our new home one day!; Dear X, belated birthday greetings. Looking forward to seeing you in Caux this year. Warmest wishes, Y; Happy birthday X! Hope $Y$ 's presentation event goes well! $X$.

Here again we see a very similar distribution of this strategy, which could be subsumed under Brown and Levinson's exaggerating and/or intensifying interest in the hearer. The highest number of such additional topics was recorded with the British, with 33 items in all, and this time with a preference for it manifested by men, who used it 20 times, while women 13 times. The more specific distribution across dyads was as follows: women-women $2+4$, women-men $2+5$, men-men $1+7$, men-women $8+4$. The general, though very tentative tendency to opt more for tackling other topics in relation to older persons when one shows interest in them might be considered as safe, on the other hand, men showing interest in younger women may have a different aim of indicating to them that they are important and attractive.

Polish FB users chose to tackle other topics 24 times, and here the distribution was quite balanced. Women used it 13 times (women-women $4+7$, 
women-men $1+1$ ) and men - 11 times (men-men $0+5$, men-women 5+1). There again seems to be a tendency of resorting to this strategy more often in relation to older friends, but of the same sex. Younger addressees do not attract as much attention in this respect, unless these are younger women addressed by men, the reason for which is likely to be the same as in the case of the British.

Indian users chose to show interest in other issues than birthday alone 22 times, which was also quite evenly spread between the sexes, viz. women used it 10 times, men 12 times. The specific distribution showed what follows: women-women $3+4$, women-men $2+1$, men-men $5+1$, men-women $4+2$. With these low figures it is hard to draw any reliable observations about preferences, on the whole, however, senior persons this time are not addressees of such comments very often, possibly out of respect, yet more likely because Indian wishes tend to be short and quite conventional overall.

The group with the lowest ratio of such comments were Armenian users, much as in the previous category. They chose to refer to other topics only 8 times. 6 cases of these were found with women (women-women $0+6$, womenmen $0+1$, and only one man addressed a young man about such an issue). This is an interesting distinction compared to the other cultures studied here, which again is possibly linked with the importance of the occasion, but at the same time a somewhat conservative approach to wishes and birthday which, as one can assume, needs to be celebrated in the Armenian culture without distraction.

\section{Multimodality}

The last section of the analysis will deal with other aspects of offering wishes on FB. Their role, as could be deduced, is twofold - to make the reading of the wish more affective, and hence more genuine, and also more individually oriented. The discussion of multimodal aspects will be divided into two subsections - the first will focus on smileys and punctuation, and the second on audio-visual aspects of the analysed wishes.

As it appears, the use of smileys and other markers of emotional display is very widespread on social media, and no doubt very useful as a conveyor of the actual emotional state of the sender. The majority of the posts analysed 
contained exclamation mark or marks, which no doubt informed the addressee that the reading of it is emphatic and conveys a serious and genuine intention of the wish. Side by side with it there was also a frequent use of smileys which, in turn, indicated what the humorous comments did in the wishes - it shortened the distance between the sender and addressee and stressed the quality of contact as that of close friends who know each other so well that they can joke about the occasion too.

The overview of the samples from the four cultures marks visible differences in terms of the use of the devices. This time it was the Polish group that made use of emphatic markers most, with 205 instances. As could have been expected, it was women who opted for it far more, with 119 instances, as opposed to men with 86 instances. However, while the women-women wishes resulted in $48+42$ such instances, the women-men dyads, with $4+25$ items showed very clearly that being too emotional with young men in public is not very acceptable and may be misread in their intentions. When men offered wishes, they chose a different pattern - in men-men dyads the distribution was 23+36, which shows that offering wishes to other men may be an FTA to the senders, and by opting for a smiley (rather than exclamation mark) may alleviate the impact of it. When addressing women, however, with 22+5 items, it can be seen that the age difference seems to restrict displays of emotionality in a visible way.

British users were also quite lavish in their use of the emphatic markers here, but with 145 items they fell significantly behind the Polish users. The distribution again pointed to a much higher preference for it on the part of women, with 86 items, as opposed to 59 items with men. It could be noted that women were most emotional with other women, viz. 30+21, and less so with men $17+18$. On the other hand, men were altogether less emotional with other men, especially young ones, viz. $6+15$, while their emphasis grew when interacting with women, viz. 29+9. This distribution confirms results of earlier studies of women being more emphatic than men, and men tending to restrict their emotions when with other men (cf. e.g. Holmes 1995). 
The overall number of emphatic markers among Armenian users was similar to that of the British, viz. 139. However, when broken according to gender, the result showed without doubt that it is a feminine domain, with 119 items, versus only 20 for men. Much as in the Polish group, women were most emphatic with other women, 39+39, but with men only when the addressees were older, viz. 8+33 (this restriction did not seem to apply in the case of the Brits, on the other hand). When men were senders, the distribution was thinning with age, but balanced, viz. men-men $7+7$, and men-women $3+3$. Thereby Armenians seem to share with Poles the reluctance on the part of men to be openly emphatic, and with the British and Poles too in the case of women to be emotional in their wishes.

These observations will not be corroborated in the Indian group, who used emphatic markers only 75 times (i.e. three times less than Poles). These were very evenly distributed across the genders, with 39 used by women and 36 by men. However, when women sent wishes, they opted for some display of emotions with other women and young men too, but not with senior men, viz. women-women $12+17$, women-men $10+0$, which was on the whole observed in the case of all other aspects, viz. elaboration of the form, other topics, humour, reinforcement, etc. To some extent similar choices were made by men, with men-men $15+3$, and men-women $8+10$ (this distribution reflects the situation found in the use of elaboration of form and content), which in a way confirms the need for respect in interaction with older men. On the whole Indian users utilised the lowest number of strategies and devices of all the cultures studied here, which leads to a conclusion that in their case birthdays need to be noticed in public, but public space is not for lavish celebrations of it for sure.

The other aspect that added up to the personalised feeling of the wishes is that of additional audio-visual aspects that enhanced the special individualized and festive reading of the message, and that also has drawn attention to cultural differences in this respect. It needs to be clarified that the audio-visual materials fall into three categories viz. probably the most common use of the coloured background and bigger font (which is offered as an option by FB, but has to be specially chosen by the user), the addition of a birthday card (much less 
frequently a photo with flowers), often with a text with additional wishes, uploaded on purpose by the user, and, rather infrequently, a short video feature prepared by FB on the occasion of the addressee's birthday that the user may choose to upload on their friend's profile for the public to see.

The analysis of this aspect shows again a visible gradation of these features across the four cultures presented in the declining order. This time the group that has by far exceeded others in terms of preference for the multimodal devices is the Armenian group, as the strategy was used 80 times (60 cards, 18 coloured backgrounds, 2 videos), so by almost a half of the users studied here. However, the distribution across genders shows a vast difference in this respect, with women having chosen it 73 times and men - only 7. Much as in the case of emphatic markers, the women-women dyad showed 26+28 examples, but women men $-3+16$ (mirroring the exclamation mark use to a large extent). Men very rarely used the device, with the subdivision presenting what follows - men-men 3+1, men-women $1+2$. Thus, it seems that celebrating birthday on FB in a grand way in Armenia is especially a female domain (particularly as regards the use of cards), while men shy away from such public displays of affection.

Compared to the Armenian result, the second culture that followed, with only 38 (16 cards, 17 coloured backgrounds, 5 videos) examples in all was the Polish group. Here again it was the females that chose this device much more often, with 26 items in all, compared to men with only 12 recorded items. When women sent wishes, the choice of the strategy was distributed as follows: women-women $6+8$, women-men $2+10$, which once again demonstrated some reluctance on the part of women to show affection with young men this way. On the other hand, it is the young men who were addressees of such wishes from other men, viz. men-men $5+3$, and female addressees were sent cards more often when they were young, viz. $4+0$.

The Indian group opted for the audio-visual enhancement of the wishes 26 times (what is noteworthy, this time with as many as 18 coloured backgrounds, 7 videos and only 1 card); both women and men sent 13 such wishes each. However, with female senders this happened almost exclusively in wishes to 
other women, viz. $9+3$, while almost never with men - women-men $0+1$. The numbers were low also in the case of men, but there the distribution was more equal, with men-men $3+6$, and men-women $3+1$. It thus appears that women showing high affection by means of ornamented wishes to men is a strong FTA for women on Facebook and it seems to be better to be avoided.

Last in the list is the British group, which, as could be assumed, would be a model for the others as a group which most likely started to use FB before the other three cultures and which uses English as a native language. Thus, other cultures copied many strategies and models from the British users, yet the use of cards, which the British appear to use very sparsely has gained popularity outside the UK and developed independently, for the British group used the audio-visual aspects only 14 times ( 5 cards, 4 coloured backgrounds and 5 videos), 9 times by women and 5 times by men. The distribution within the group was also rather unequal, with women-women $0+6$, and women-men $2+1$. In the case of men, the men-men dyad produced $3+1$ items, and men-women, $1+0$, it can thus be seen that the preference for this device is low, and in keeping with a fairly moderate display of emotions on the part of the Brits.

\section{Conclusion}

The above analysis has demonstrated that each of the four cultures has some unique aspects of offering birthday wishes online. In particular:

The British employed terms of address expressed by first names frequently and in an equal manner to all types of addressees irrespective of their gender and age. They relied on conventional forms in $66 \%$ of cases. In the pesonalised forms they used elaborated forms most of all the groups, and the strategy was found in all the types of dyads, yet most of all in the women-women followed by women-men dyad. An additional device, reinforcement of empathic forms, was found in a limited number of cases, yet most frequently out of all the four cultures, typically in posts written by women. British users relied on informality and humour to some extent (the second highest ratio, but close to Poles and Indians), with a greater share of informal markers which were, interestingly, used by women to women, the other dyads using the device 
rather sparsely. British users personalized their wishes by means of referring to other topics too, most of all the four cultures, but this time it was men who made use of the device more. In the case of multimodal markers of affectiveness, the punctuation and smileys, British users of both genders used them quite sumptuously, though with a visible preference for them on the part of women. It seems that young women were also most typical addressees of such wishes. Finally, the audio-visual markers of affectiveness in wishes (cards, videos, coloured formats), were employed by Brits very restrictively, as those strategies hardly featured in the samples (most of all, when addressed to older women), which indicates that British users do not see a need to celebrate birthday online in a excessively lavish manner.

Poles used the lowest number of terms of address, they avoided using formal titles, yet they diversified the meaning conveyed by the form of the name (by means of different cases and the choice of full or diminutive forms), and used them least in the men-women dyads and women-young men dyads. The conventionalised forms were found in $65 \%$ of cases, i.e. with almost the same frequency as with the Brits. The highest share of the use of this device was also found with women-women dyad, much less in the others, especially in men-women. A reinforcement of emphatic forms was quite rare, with the third ratio among the four cultures, and also used mostly by women. Poles used humour and informality markers less often than Brits, but unlike the other groups, with the predominance of humour over informality, which was found especially in men-men dyads. Poles relied on the strategy of employing other topics less than Brits and with a similar frequency as regards women and men, though possibly less often in posts addressed to men. When it comes to the use of multimodal affective markers, Poles most certainly exceeded other groups in the frequency of their use. As in the case of Brits, it was women in particular who used them in their wishes, but especially to other women, while they withheld their use when sending wishes to young men, unlike men, who, in turn, limited their use when addressing older women. Poles used the audiovisual markers more than twice as often as the Brits, opting for cards and coloured formats in similar numbers. Though the overall number of the 
markers was not very high, the preference of women for this strategy is certainly visible.

Indians used a fair number of terms of address, both formal (with typical Hindi and English honorifics) and informal ones, the main restriction being the use of titles by women towards men. Indian users relied on the conventional forms (primarily in English), using them in $78 \%$ of cases. In the personalized forms the elaboration of form and content was used least of all the groups, and mostly by women to women, while the other dyads were hardly marked by the strategy. Reinforced forms were rare, with the second ratio after Brits, and characterized women's wishes. Indian users made use of the highest number of humour and informality strategy, and the two were used in a fairly balanced way by both women and men, yet humour specifically was hardly employed as opposed to the predominance of informality, which typically marked women's posts. Indian users relied on other topics as devices of personalization slightly less than Poles, and with a similar frequency as regards men and women. In the case of multimodal affective markers Indian users were most restrained of all, with only a half of the number found with the Brits. Again, the women-women dyads were marked by them most, while male addressees hardly ever received wishes marked this way. The use of the audiovisual multimodality markers was likewise rather limited in the Indian group. Although the total number was twice as large as that found with the British, and the distribution between women and men was equal, the examination of the sample shows the markers were not typically employed in mixed-sex dyads.

Armenian users used almost as many forms of address as the British did, yet they did include formal titles to a large extent, besides, they relied on the use of the Armenian term of endearment jan a lot, both with names and formal forms of address. They also made a much more frequent use of the form dear than the British users (37 items vs. 4). Armenian users relied on conventional forms as often as Indians, i.e. in $77 \%$ of the cases, and they used them often both in English, Armenian, and Russian. Personalisation was achieved by elaboration of form more than in the case of Indians, yet here also it was most typically found in women-women dyads, the other dyads, with the exception of women-older 
men were hardly marked by the strategy. Reinforced forms were infrequently recorded too. They had the lowest ratio, and with one exception, were used by women. Humour and informality were nearly missing from Armenian posts, notably the former, found only once. Informal markers were noted in posts written almost always by women. Armenian users hardly ever related to other topics, and this strategy, if at all, appeared in posts written by women (with one exception). As regards the affective use of multimodal markers, Armenian users often employed them, however, as it turned out, it was almost exclusively women (the ratio 6:1), and particularly when addressing other women, less so older men (contrary to younger men) that used them. Men, on the other hand, hardly chose this option of personalizing wishes to others. The use of the audiovisual markers confirmed the tendency too. Although Armenian users opted for the strategy with utmost frequency, 5 times more than the British, the detailed examination shows that it was again mostly women who chose the strategy (10 times more than men) and especially the use of cards.

The above characteristics prove that each culture has its own unique way of sending wishes to friends on SNSs, ranging from the rather restrictive ways of using the speech act typical of Indians, followed by Brits, then Poles, and ending with the very elaborate and serious treatment of wishes on the part of Armenian users. The tendencies identified above can be found both in the wishes expressed in the native language of the senders and in the other tongues used, also in English, the lingua franca of the modern world and the social media too. No doubt, some of the differences may be motivated by the differences in the cultural dimensions among the cultures (e.g. the more personalized forms resulting from a higher sense of individualism, restriction on the use of titles as a marker of lower power distance and the use of titles and honorifics as manifestations of higher power distance and possibly masculinity, as well as a more frequent use of humour as a tool protecting against uncertainty, etc.), yet the relationship between the form and content of the wishes and the dimensions does not seem to be simple and straightforward. What, on the other hand, appears to foreground itself is the role of gender, which seems to influence the linguistic choices greatly in most cultures, 
especially Armenian, particularly in relation to who the addressee (i.e. a women or a man) is. The variable of age does seem to affect the linguistic choices in the case of online wishes.

\section{Notes:}

1. This classification, incidentally, can be paired up with the reactions to wishes too, as a study by Theodoropoulu (2015) based on reactions of a number of Greek users demonstrates. The author concludes that Greek users tend to opt for the much more personalized, individualized form of thanks than just posting a general thank you post on their walls.

\section{References:}

1. Archer, D.; Aijmer, K.; Wichmann, A. (2012) Pragmatics. An Advanced Resource Book for Students. London and New York: Routledge, Taylor and Francis Group.

2. Blommaert, J. (2010) The Sociolinguistics of Globalization. Cambridge: CUP.

3. Blommaert, J. (2018) Durkheim and the Internet. Sociolinguistics and the Sociological Imagination. London, New York, Oxford, New Delhi, Sydney: Bloomsbury Academic.

4. Blum-Kulka, S. (1983) Interpreting and Performing Speech Acts in a Second Language: Across Cultural Study of Hebrew and English SocioLinguistics and Language acquisition. Rowley: Newbury House.

5. Brown, P. and Levinson, S.C. (1978/1987) Politeness. Some Universals in Language Usage. Cambridge: CUP.

6. (2010) Business Management in Armenia Available at: <http://www.freeonlineresearchpapers.com/business-managementarmenia> [Accessed February 2019].

7. Can, H. (2011) A Cross-Cultural Study of the Speech Act of Congratulation in British English and Turkish Using a Corpus Approach. Unpublished MA Thesis, Ankara: Middle East Technical University. Available at: 
$<$ http://citeseerx.ist.psu.edu/viewdoc/download?doi=10.1.1.633.7153\&rep $=$ rep1\&type $=$ pdf $>$ [Accessed January 2019].

8. Coulmas, F. (1981a) Introduction: Conversational Routine. // Conversational Routine. Explorations in Standardized Communication Situations and Prepatterned Speech. / Ed. by F. Coulmas. Berlin: De Gruyter, 1-18.

9. Dąbrowska, M. (2007a) Modifiers in Male and Female Expressions of Emotions. // B.A.S. British and American Studies. / Ed. by H. Parlog. Timisoara: EUV Editura Universitătii de Vest, 245-254.

10. Dąbrowska, M. (2007b) Female Acts of Identity// Journal of Languages and Translation. Vol III - No II, Part II A Special Issue for the Proceedings of the Fourth International Conference of the Faculty of Al-Alsun, Minia University "Preserving Linguistic and Cultural Identity in the Age of Globalization.” / Ed. by A.M. Kamal. Minia: Minia University Printing House, 632-654.

11. Dąbrowska, M. (2013) Variation in Language: Faces of Facebook English. Frankfurt am Main: Peter Lang Edition.

12. Dąbrowska, M. (2018) Abbreviated English - a typical feature of online communication? // Studia Linguistica Universitatis Iagellonicae Cracoviensis 135, 235-251.

13. Dąbrowska, M. (2019) Politeness, Gender, and English-Medium Facebook Communication. // Rhetoric and Communications E-Journal 40/2019, 117146.

14. Danesi, M. (2016) Language, Society, and New Media. New York/London: Routledge Taylor and Francis Group.

15. Goebel, Z. (2017) Superdiversity from within: The Case of Ethnicity in Indonesia. // Engaging Superdiversity. Recombining Spaces, Times and Language Practices / Ed. by K. Arnaut, M.S. Karrebæk, M. Spotti and J. Blommaert. Bristol: Multilingual Matters, 251-276.

16. Hall, E.T. (1966) The Hidden Dimension. New York: Doubleday.

17. Hall, E.T. (1976) Beyond Culture. New York: Random House. 
18. Hofstede, G. (1980) Culture's Consequences: International Differences in Work-Related Values. Newbury Park, CA: Sage.

19. Hofstede, G. (2001) Culture's Consequences. Comparing Values, Behaviours, Institutions, and Organizations across Nations. 2nd edn. Thousand Oaks: Sage Publications Inc.

20. Holmes, J. (1995) Men, Women and Politeness. London and New York: Longman.

21. Hofstede Insights. Available at: <https://www.hofstedeinsights. com/country-comparison> [Accessed January 2019].

22. Khachatryan, N.; Manusyan, S.; Serobyan, A.; Grigoryan, N. and Hakobjanyan, A. (2014) Culture, Values, Beliefs: Behaviour Guidelines In Changing Armenian Society. Yerevan: YSU.

23. Khzrtian, S. and Samuelian, T. (2012) The Armenian Culture of Negotiation: Research Approaches, 24-32. Available at: $<$ http://ysu.am/files/ 04S_Khzrtian_T_Samuelian.pdf> [Accessed January 2019].

24. Kirkman, B., Lowe, K.B.and Gibson, C.B. (2006) A quarter century of Culture's Consequences: A Review of Empirical Research Incorporating Hofstede's Cultural Values Framework. // Journal of International Business, 37: 285-320.

25. Kotorova, E.G. (2014) Describing Cross-cultural Speech Behavior: a Communicative-Pragmatic Field Approach. // Procedia - Social and Behavioral Sciences 154 (2014) 184-192.

26. Leppänen, S. and Elo, A. (2016) Buffalaxing the Other: Superdiversity in Action on YouTube. // Language and Superdiverity. / Ed. by In K. Arnaut, J. Blommaert, B. Rampton and M. Spotti. London/New York: Routledge, 110-130.

27. Liao, C. (2000) Intercultural Emailing. Taipei: The Crane Publishing Co, Ltd.

28. Lubecka, A. (2000) Requests, Invitations, Apologies and Compliments in American English and Polish. A Cross-Cultural Communication Perspective. Kraków: Księgarnia Akademicka. 
29. Mekeko, N.M. (2001) The Comparative Analysis of Speech Etiquette Unit Functioning Within the Thematic Group "wishes" in English and Russian. Dissertation in Philology. Moscow.

30. Merriam-Webster Dictionary. Available at: <https://www.merriamwebster.com/> [Accessed December 2018].

31. Nurgalieva, L. and Saidasheva, E.A. (2017) The Role of Wishes in Tatar and English Linguistic Cultures. // Journal of History, Culture and Art Research Vol. 6(4), 1292-1304.

32. Pauwels, L. (2012) A Multimodal Framework for Analyzing Websites as Cultural Expressions. // Journal of Computer-Mediated Communication 17.3: 247-265.

33. Searle, J.R. (1975) Indirect Speech Acts. // Syntax and Semantics, Vol. 3: Speech Act Cole / Ed. by P. \& J. L. Morgan. New York: Academic Press, 5982.

34. Searle, J.R. (1976) A Classification of Illocutionary Acts. // Language in Society, 5(1), 1-23.

35. Stæhr, A. (2017) Languaging and Normativity on Facebook. // Engaging Superdiversity. Recombining Spaces, Times and Language Practices / Ed. by K. Arnaut, M. S. Karrebæk, M. Spotti and J. Blommaert. Bristol: Multilingual Matters, 170-195.

36. Tannen, D. (1990) You Just Don't Understand. Women and Men in Conversation. New York: Ballantine Books.

37. Theodoropoulou, I. (2015) Politeness on Facebook: The Case of Modern Greek Birthday Wishes // Special Issue: Relational Work in Facebook and Discussion Boards/ For a... / Ed. by M.A. Locher, B. Bolander, and N. Höhn. Pragmatics 25(1), 23-45.

38. Trompenaars, F. and Hampden-Turner, C. (1997) Riding the Waves of Culture: Understanding Diversity in Global Business; $2^{\text {nd }}$ ed. London: Nicholas Brealey Publishing.

39. Varis, P. (2016) Superdiverse Times and Places: Media, Mobility, Conjunctures, and Structures of Feelings. // Engaging Superdiversity: 
Recombining Spaces, Times and Language Practices. / Ed. by K. Arnaut, M. Karrebæk, M. Spotti and Jan Blommaert. Bristol: Multilingual Matters, 25-46.

40. Varis, P. and Vang, X. (2016) Superdiversity on the Internet: A Case from China. // Language and Superdiverity. / Ed. by K. Arnaut, J. Blommaert, B. Rampton and M. Spotti. London/New York: Routledge, 218-236.

41. Vertovec, S. (2006) The Emergence of Super-Diversity in Britain. Centre on Migration Policy and Society. Working Paper 25. Oxford University.

42. Viswanath, B.; Mislove, A.; Meeyoung, C.; Gummadi, K.P. (2009) On Evolution of the Interaction on Facebook. // Proceedings of the $2^{\text {nd }}$ ACM SIGGCOM Workshop on Social Networks. / Ed. by J. Crowcroft and B. Krishnamurthy, New York: ACM Press, 37-42.

43. West, L. and Trester, A.M. (2013) Facework on Facebook. Conversations on Social Media. // Discourse 2.0. Language and New Media / Ed. by D. Tannen and A.M. Trester. Washington, D.C: Georgetown University Press, 133-154.

\section{Suptinupd, u2ulynujp li ungưtiphu}

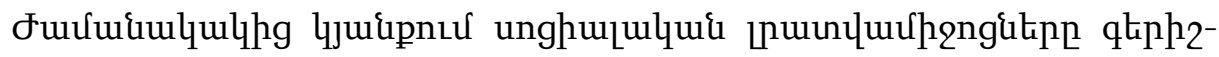

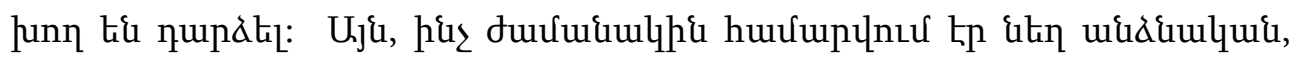

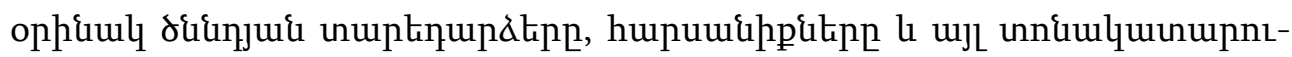

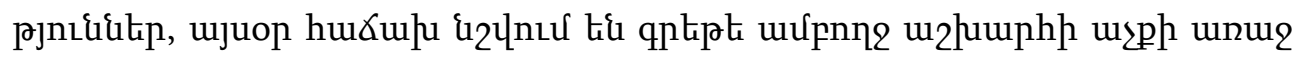

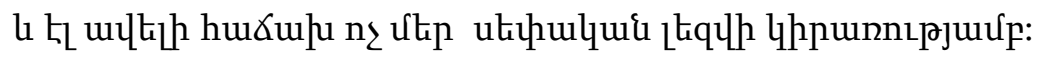

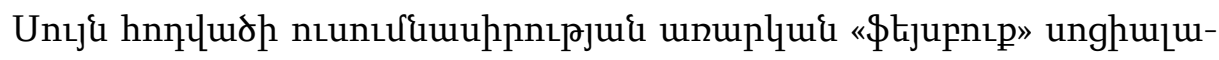

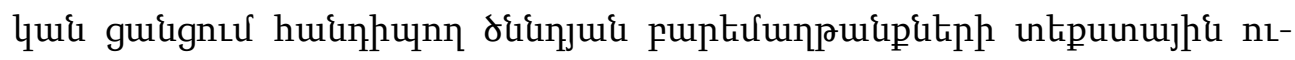

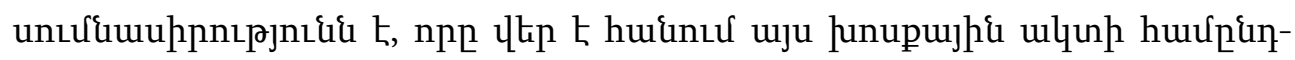

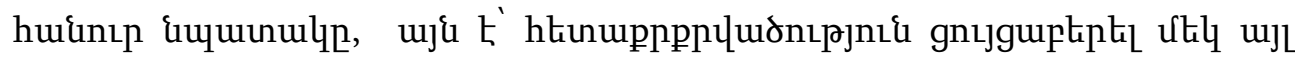

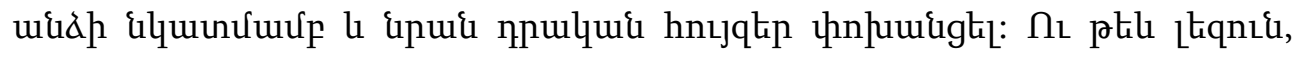

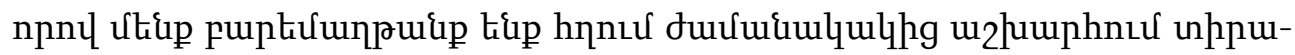

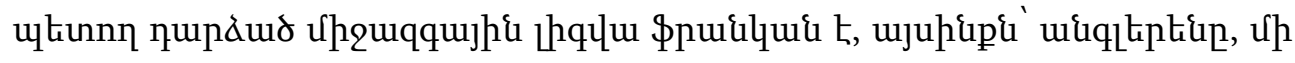

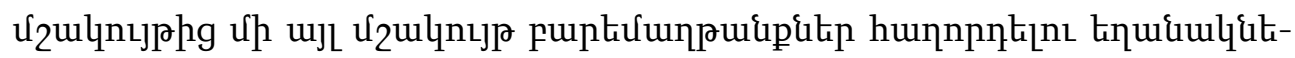




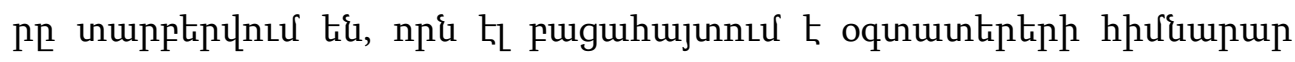

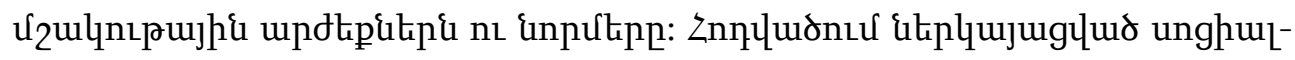

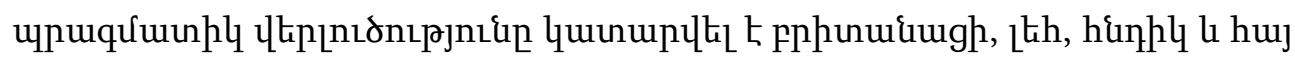

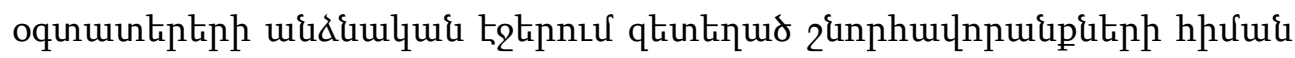

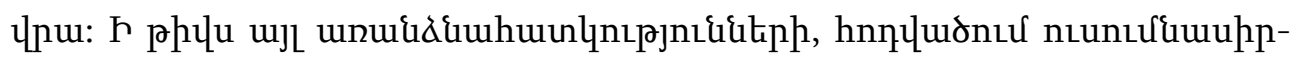

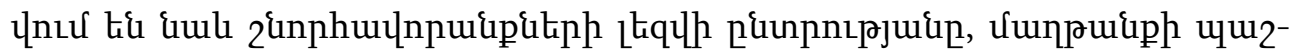

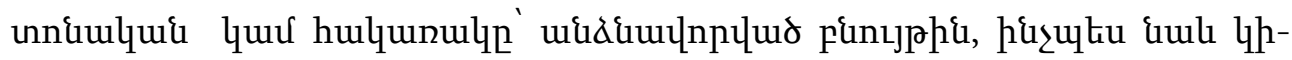

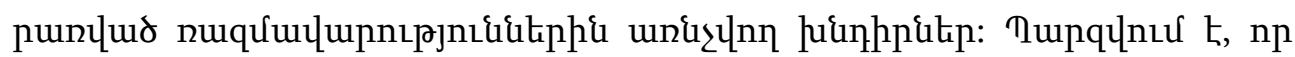

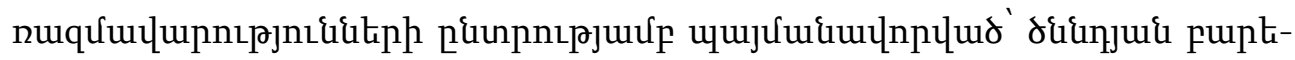

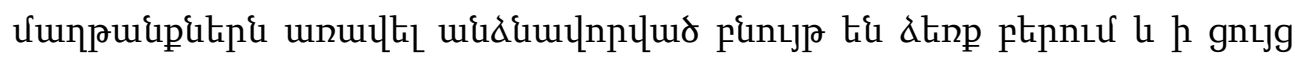

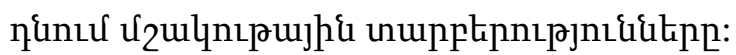

Received by Editorial Board 12.09.2019

Recommended for publication by Reviewers 24.10.2019

Accepted for Print 01.11.2019 